\title{
Evaluating environmental radiations of the tomotherapy facility by optimizing full factorial design of the TLD technique
}

\author{
Zhangmin Shen ${ }^{\mathrm{a}}$, Ying-Hsiang Chou ${ }^{\mathrm{a}, \mathrm{b}, \mathrm{c}}$, Cheng-Chang Lu ${ }^{\mathrm{a}, \mathrm{b}}$, Ren-Jing Huang ${ }^{\mathrm{a}, \mathrm{b}}$, \\ Ching-Hsiu Ke ${ }^{\mathrm{d}, \mathrm{e}}$, Lung-Kwang Pan $^{\mathrm{d}, *}$ and Chien-Yi Chen ${ }^{\mathrm{a}, \mathrm{b}, *}$ \\ ${ }^{a}$ Department of Medical Imaging and Radiological Sciences, Chung Shan Medical University, Taichung, \\ Taiwan \\ ${ }^{\mathrm{b}}$ Department of Radiation Oncology, Chung Shan Medical University Hospital, Chung Shan Medical \\ University, Taichung, Taiwan \\ ${ }^{\mathrm{c}}$ School of Medicine, Chung Shan Medical University, Taichung, Taiwan \\ ${ }^{\mathrm{d}}$ Department of Medical Imaging and Radiological Science, Central Taiwan University of Science and \\ Technology, Takun, Taichung, Taiwan \\ ${ }^{\mathrm{e}}$ Department of Optometry, Central Taiwan University of Science and Technology, Takun, Taichung, \\ Taiwan
}

\begin{abstract}
.
BACKGROUND: In the last 40 years, the number of deaths due to cancer has been the highest in Taiwan

OBJECTIVE: To optimize the readout system of the thermoluminescent dosimeter (TLD)-100H, the radiation rates among the Tomotherapy (TOMO) facility of the Department of Radiology Oncology of Chung Shan Medical University Hospital (CSMUH) were calculated with a $3^{2}$ full factorial design (FFD).

METHODS: A ten-month survey of the facility was employed using the sensitive and accurate TLD method. The TLD system was optimized for maximum temperature, heat rate, and preheat temperature of Harshaw 3500 reader. Eight analyzed groups with different factors were tested.

RESULTS: The TOMO facility had significantly different radiation rates. The farther away from the gantry head, environmental radiation rates. The half value layer (HVL) was also determined. These results were compared with published. No significant contributions of environmental gamma radiations were detected except in the treatment room.

CONCLUSIONS: Those were far below the occupational doses recommended by ICRP 60 .
\end{abstract}

Keywords: Full factorial design, tomotherapy facility, environmental radiations, thermoluminescence dosimeter (TLD), half value layer (HVL)

\section{Introduction}

In the last 40 years, the number of deaths due to cancer has been the highest in Taiwan [1]. High-

\footnotetext{
${ }^{*}$ Corresponding authors: Chien-Yi Chen, Department of Medical Imaging and Radiological Sciences, Chung Shan Medical University, Taichung 40201, Taiwan, Department of Radiation Oncology, Chung Shan Medical University Hospital, Chung Shan Medical University, Taichung 40201, Taiwan. E-mail: chien.ccy@ gmail.com and Lung-Kwang Pan, Department of Medical Imaging and Radiological Science, Central Taiwan University of Science and Technology, Takun, Taichung, Taiwan. E-mail: 1kpan@ctust.edu.tw.
} 
energy radiations were generated by linear accelerator (linac), exposing staff and patients to undesirable radiations due to gantry head leakage during operations [2-6]. These radiations do not belong to routine treatment planning. A detailed survey is important to evaluate the extra radiations spread within this facility. Many published studies consider the thermoluminescent dosimeter (TLD) as one of the most effective approaches in dramatic radiations [3-9].

Nowadays, full factorial design (FFD) has proved its applicability and is widely used in the planning of experiments [10-13]. FFD is an useful tool in the characterization of radiation measurements by studying the interactions of factors and effects [12,13]. The applications of experimental designs provide many investigations of how different levels will affect analysis factors of the Harshaw 3500 reader (Harshaw Company, Bicron NE, OR Solon, OH, USA), instead of the traditional one-variable-at-a-time experiments They are used by a majority of researchers [9-13].

The appropriate heating rate $\left({ }^{\circ} \mathrm{C} / \mathrm{s}\right)$, maximum temperature $\left({ }^{\circ} \mathrm{C}\right)$ and initial temperature $\left({ }^{\circ} \mathrm{C}\right)$ are critical factors of FFD in the Harshaw 3500 reader of the TLD approach. In addition, a well-designed TLD readout system calculates specific doses with good reliability. It can be used ranging from $10^{3}$ to $10^{-1} \mathrm{mSv} / \mathrm{mo}$ of environmental radiations of the tomotherapy (TOMO) facility (Hi-Art Tomotherapy, Inc, Madison, WI, USA) $[3,14,15]$. Sadeghi et al. stated that the storage temperature, readout time, maximum temperature of readout, heating rate, preheat time, preheat temperature, exposure to readout time, annealing to exposure time, annealing time, and annealing temperature were important factors of FFD in the Harshaw reader of the TLD approach [9]. Specifically, the TLD readout factors should be sensitive to dramatic variations in the environmental radiations of the TOMO facility during the one-month survey. An FFD has a significant effect on the response factor and the variations in the effect of one independent factor due to level of another factors [10-13]. In the field of environmental radiations of the TLD approach via the analysis factors of TLD reader, only a few studies using the FFD of experiments were published [9]. The present study aimed to report the optimization of reaction factors using a $2^{3}$ FFD analysis on the environmental radiations via the TLD approach. The TLD-100H reading system was optimized for useful analytical conditions of linac of Chung Shan Medical University Hospital. This application of TLDs was critical to confirm that radiotherapy beams doses, as doses administered in a single treatment is around 10 to 350 cGy $[2,5,6]$.

\section{Method}

\subsection{Tomotherapy facility}

Figure 1a shows the TOMO treatment room, and $1 \mathrm{~b}$ shows the plane view of the TOMO facility at the Department of Radiation Oncology (DRO) of Chung Shan Medical University Hospital (CSMUH) [14,15]. This facility is located on the first floor $(1 \mathrm{~F})$ and includes the TOMO treatment room, archives room, control room, magnetic resonance imaging (MRI) facility, waiting room, and computer room. A 120-cmthick reinforced concrete $(\mathrm{RC})$ wall and a $250-\mathrm{mm}$-thick lead $(\mathrm{Pb})$ wall were employed in the construction of primary barriers between the archives room, control room, and waiting room. The treatment room is 9.0 meter long $\times 5.0$ meter wide $\times$ and 3.0 meter high. A sliding door, made of a $4.5-\mathrm{cm}$-thick steel plate $(\mathrm{Fe})$, was installed between the treatment room and the waiting room. The sliding door has a motorized opener due to its heavy weight. A 90-cm-thick RC and 20-cm-thick steel plate (Fe) was installed between the upper floor (2F), that is, the office room. In addition, a 210-cm-thick RC plate and a 20-cm-thick Pb plate were installed between basements (B1) and Axesse (Elekta 2538) linac, respectively [14,15]. Spot $\mathrm{D}_{1}$ was located in the middle of the sliding door and visible from the gantry center (Fig. 1b). 

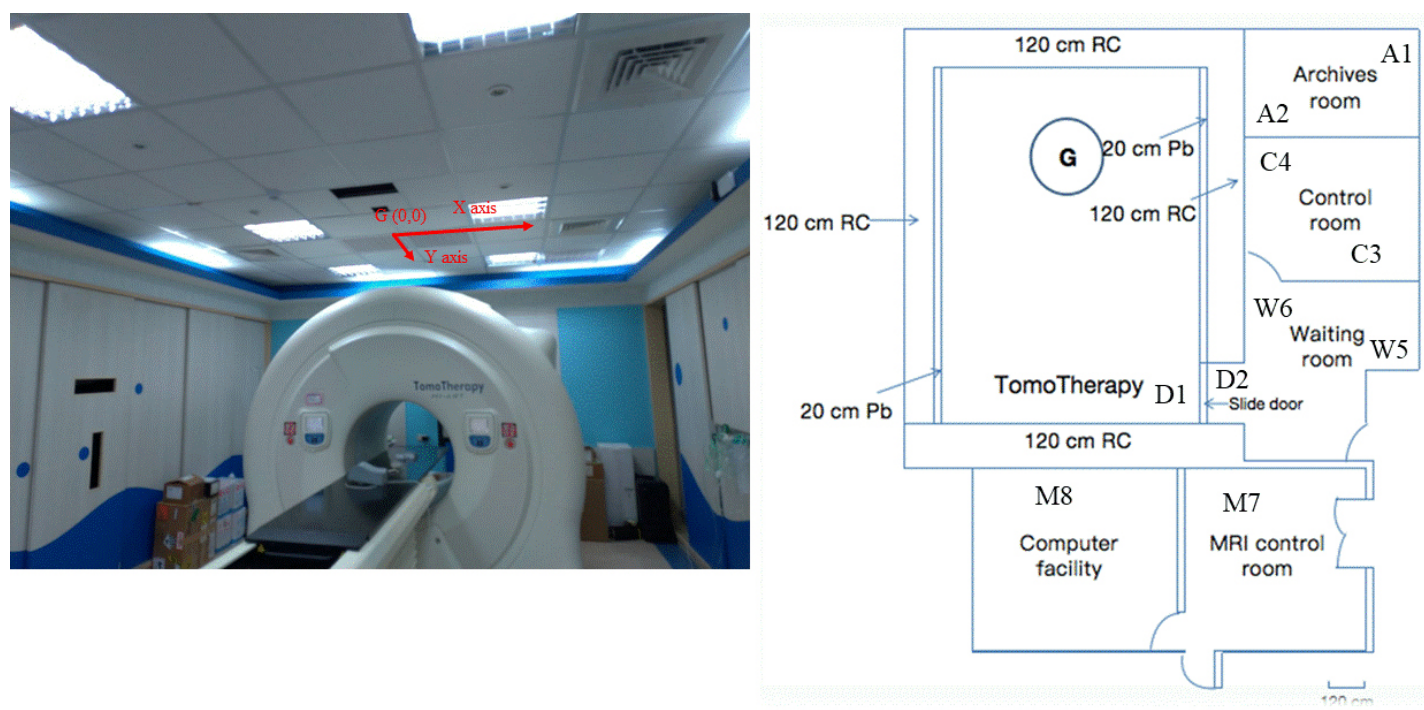

Fig. 1. (a) TOMO treatment room (b) the floor plan of the TOMO facility.

These extra radiations are health concerns for the public. Thus, the TOMO facility must be exactly shielded to keep the radiations as low as reasonably achievable (ALARA) for the safety of the doctors, radiologists, and the general public [14,16]. From 10 January to 10 September 2020, and from 29 January to 5 March 2021 (including five holidays during the Chinese New Year), 3701 patients treated for bone limb (178), pelvic cancer (665), abdominal cancer (260), breast cancer (1362), as well as head and neck cancer (1236) were included in this study [15].

\subsection{TLD-100 system}

The TLD-100 has been used for calculating environmental radiations for the last three decades because TLD indicates long time accumulation of radiations [3-9]. To find the optimum group for environmental radiations using TLD-100H, one must find the optimum levels for the factors of Harshaw 3500 reader using FFD. The TLD-100H (Harshaw Company, Bicron, NE, OR Solon, OH, USA) made of LiF:Mg, $\mathrm{Cu}$, $\mathrm{P}$ used around $2.8 \times 2.8 \times 0.9 \mathrm{~mm}^{3}$.

\subsection{Surveying environmental radiations}

The TLDs were randomly tapped on the light steel joint ceiling of the TOMO facility during the one-month survey to evaluate the distributions of environmental radiations, as shown in Fig. 2 [5]. Each light steel joint was $0.6 \times 0.6 \mathrm{~m}^{2}$. A spot $\mathrm{G}(0,0)$ was defined as the geometric origin in the light steel joint ceiling of the center of the TOMO gantry head; all dimensions are quoted in meters.

Automatically, the Harshaw 3500 reader was used to read irradiated TLD chips after the 1-month monitor as described in previous studies [2-9]. Moreover, Tseng et al. used highly sensitive TLDs to evaluate leakage photon doses around the linac providing Volumetric Modukated Arc Therapy [3]. To eliminate the fluctuation of the TLD-100H, 3 TLDs were combined in $1 \mathrm{bag}$, so that 321 TLDs representing 107 measurement locations using reusable TLDs. 2 bags (6 TLDs) were used to monitor the environmental radiations in Taichung, about 500 meters (female dormitory) and 1000 meters (professor's home) away from CSMUH. They were labeled as TC1 and TC2, respectively. Four bags, i.e. 12 TLDs 
Table 1

Experimental levels and factors for the optimization experiments of the settings of the TLD Harshaw 3500 reader

\begin{tabular}{lcc}
\hline Experimental factors & Level 1 & Level 2 \\
\hline Initial temperature $\left({ }^{\circ} \mathrm{C}\right)$ & 130 & 140 \\
Heating rate $\left({ }^{\circ} \mathrm{C} / \mathrm{s}\right)$ & 9 & 11 \\
Maximum temperature $\left({ }^{\circ} \mathrm{C}\right)$ & 230 & 250 \\
\hline
\end{tabular}

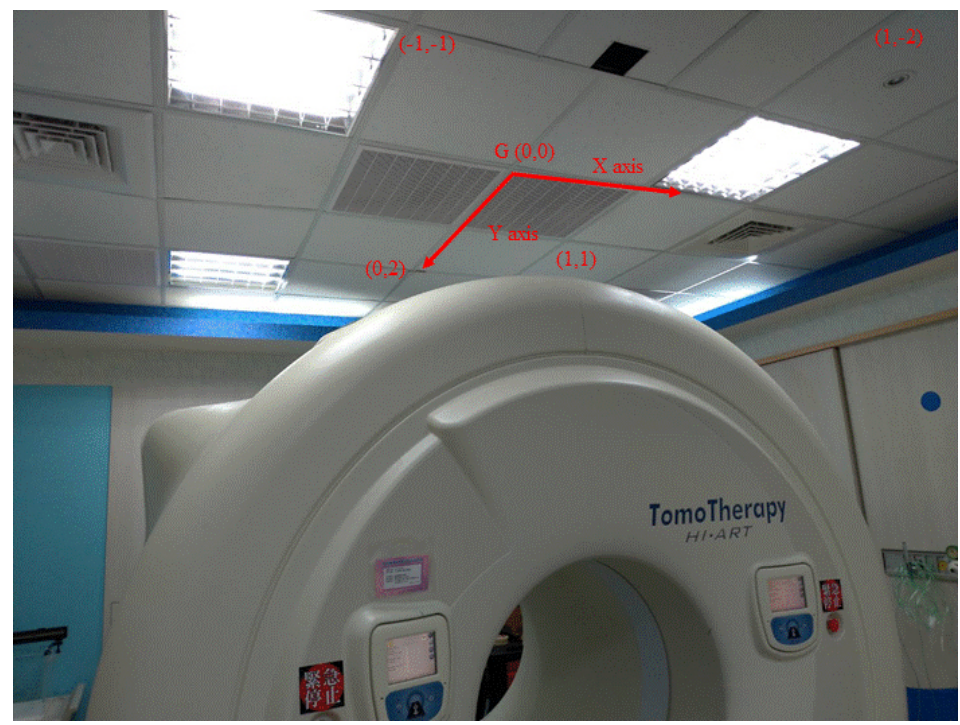

Fig. 2. TLDs were attached on the ceiling of the TOMO facility during the survey.

were used to evaluate the background radiations in the lower background laboratory [3-5]. The results of each bag were mean after one-month of monitoring. The counting statistics, calibration, and fluctuations of the reader for the calibrated TLD- $100 \mathrm{H}$ were less than twenty \% [5]. The environmental radiations were evaluated as distance from spot $\mathrm{G}(0,0)$ in the treatment room, which were interpolated between the monitored spots at each distance. In addition, measuring radiations at several spots at the same distance, mean environmental radiations were used. TLDs were counted and analyzed to evaluate the environmental radiations in this treatment room.

\subsection{Full factorial design (FFD)}

In an FFD, data are evaluated among all combinations of the experimental factor. To find an optimum protocol for (A) initial temperature, (B) heating rate, and (C) maximum temperature, a two-level FFD model was used, as shown in Table 1. Each factor was studied on two levels $\left(2^{3}\right.$ design). So that, a total of $8(2 \times 2 \times 2)$ different combinations were selected based on the original settings, as listed in Table $1[6,9-11]$. The mean of three runs of the independent experimental factors in correlation with the data were published. This design and analysis of data were evaluated by the statistical software Excel [17]. To prevent reduction of the TLD's damage and sensitivity, Sadeghi demonstrated that temperatures more than $250^{\circ} \mathrm{C}$ should not be used for annealing [9].

The ratio of signal-to-noise $(\mathrm{S} / \mathrm{N}$, measured in $\mathrm{dB}$ ) was introduced to qualify the integrated levels of Harshaw 3500 reader. The factor $\mathrm{S} / \mathrm{N}$ integrates both sharp coefficient $(\beta)$ and low standard deviation 
Table 2

\begin{tabular}{cccc}
\multicolumn{4}{c}{ Variable in a $2^{3}$ full factorial design } \\
\hline Group & \multicolumn{3}{c}{ Factor/level } \\
\cline { 2 - 4 } & $\begin{array}{c}\text { A initial } \\
\text { temperature }\left({ }^{\circ}\right)\end{array}$ & Beating rate $\left({ }^{\circ} \mathrm{C} / \mathrm{s}\right)$ & Maximum temperature $\left({ }^{\circ} \mathrm{C}\right)$ \\
\hline 1 & 130 & 11 & 230 \\
2 & 130 & 11 & 250 \\
3 & 130 & 9 & 230 \\
4 & 130 & 9 & 250 \\
5 & 140 & 11 & 230 \\
$* 6$ & 140 & 11 & 250 \\
7 & 140 & 9 & 230 \\
8 & 140 & 9 & 250 \\
\hline
\end{tabular}

*G6 is original setting.

(Stdev), so that the optimum group in FFD is determined as the group with the maximum S/N value. Ideal TLD dosimeters readout must reflect the given huge radiations during the one-month survey. The TLD measurements under 1,2, and $10 \mathrm{cGy}$ of various 6-MV photon beams of TOMO for each group were calculated as follows:

$$
\eta=\frac{S}{N}(\mathrm{~dB})=-10 \log \left(\frac{\text { Stdev }}{\beta}\right)^{2}
$$

Thus, a bigger $\eta$ was considered preferable this existed only under either a smaller numerator (Stdev) or a bigger coefficient $(\beta)$. Table 2 shows eight groups of the various groups suggested by the FFD.

$$
S t d e v=\frac{1}{N-1} \sqrt{\sum_{i=1}^{N}\left(X_{i}-\bar{X}\right)^{2}}
$$

The team Stdev represented the integrated standard deviations of the repeated radiated TLD, which was averaged over three TLDs in one bag. The $\beta$ was the estimated coefficient obtained from the calibration curves of the given doses obtained for each group of the Harshaw 3500 reading.

\subsection{TLD calibration}

Twenty-four TLD-100H materials were obtained from the Harshaw Company. In FFD, TLDs was placed $15 \mathrm{~cm}$ deep in the center of solid water phantom, with a field size of $10 \times 10 \mathrm{~cm}^{2}$, and exposed 3 times for calculating the reproducibility in data experiments. The distance from detector to source was $100 \mathrm{~cm}$. The assigned doses to exposed TLDs were calibrated via a farmer-type ion chamber (IC) (type NE 2571, Nuclear Enterprises, UK), with a volume of $0.6 \mathrm{~mL}$. Simultaneously determined the doses exposed to the TLDs, the IC was inserted into a tunnel inside the solid water phantom and located below the TLDs. Every irradiated TLD background-corrected readout was obtained using each group of the Harshaw 3500 reader. Finally, TLD was annealed in furnaces made of Barnstead Int. Co. model 47,900 and then equipped with an oven (model 47900 ) at $230^{\circ} \mathrm{C}$ about $10 \mathrm{~min}$, than followed by $100^{\circ} \mathrm{C}$ for $10 \mathrm{~min}$ for TLDs [3]. Furthermore, to effectively suppress the residual doses in the next exposure, the TLDs were allowed to cool for at least one week. Three TLDs were put in one bag to compare the fluctuations in the TLDs. 321 TLDs represented 107 measured points. In addition, batch homogeneity was ensured by describing the sensitivity of each TLD $\left(S_{i}\right)$ as follows:

$$
S_{i}=\frac{R_{i}-\bar{R}}{\bar{R}} \times 100 \%
$$


Table 3

The coefficient estimate among the eight groups

\begin{tabular}{clccrr}
\hline $\mathrm{G}$ & Linear regression equation & Correlation coefficient & Stdev & \multicolumn{1}{c}{$\beta$} & \multicolumn{1}{c}{$\eta$} \\
\hline 1 & $\mathrm{Y}_{1}(\mathrm{cGy})=0.92267 \times \mathrm{X}(\mu \mathrm{C})-0.27539$ & $\mathrm{R}^{2}=0.97793$ & 0.468 & 0.92267 & 0.590 \\
2 & $\mathrm{Y}_{2}(\mathrm{cGy})=0.72186 \times \mathrm{X}(\mu \mathrm{C})-0.22239$ & $\mathrm{R}^{2}=0.98588$ & 2.464 & 0.72186 & -1.090 \\
3 & $\mathrm{Y}_{3}(\mathrm{cGy})=0.84044 \times \mathrm{X}(\mu \mathrm{C})-0.03136$ & $\mathrm{R}^{2}=0.93600$ & 0.510 & 0.84044 & 0.434 \\
4 & $\mathrm{Y}_{4}(\mathrm{cGy})=0.72564 \times \mathrm{X}(\mu \mathrm{C})-0.13434$ & $\mathrm{R}^{2}=0.99039$ & 1.351 & 0.72564 & -0.540 \\
5 & $\mathrm{Y}_{5}(\mathrm{cGy})=0.67562 \times \mathrm{X}(\mu \mathrm{C})+0.29694$ & $\mathrm{R}^{2}=0.96105$ & 1.839 & 0.67562 & -0.869 \\
6 & $\mathrm{Y}_{6}(\mathrm{cGy})=0.80806 \times \mathrm{X}(\mu \mathrm{C})-0.82931$ & $\mathrm{R}^{2}=0.95641$ & 1.072 & 0.80806 & -0.246 \\
7 & $\mathrm{Y}_{7}(\mathrm{cGy})=0.77861 \times \mathrm{X}(\mu \mathrm{C})+0.07073$ & $\mathrm{R}^{2}=0.98018$ & 1.592 & 0.77861 & -0.621 \\
8 & $\mathrm{Y}_{8}(\mathrm{cGy})=0.64446 \times \mathrm{X}(\mu \mathrm{C})-0.02510$ & $\mathrm{R}^{2}=0.97423$ & 1.189 & 0.64446 & -0.532 \\
\hline
\end{tabular}

$S_{i}$ represents the sensitivity of the ith TLD. $\bar{R}$ is the average of all TLD readings. In addition, $R_{i}$ is the measured reading on the ith TLD in this point. The measurements were taken for a one-month survey and repeated 10 times.

\subsection{Half value layer (HVL) of TOMO treatment room}

Using the following attenuation equation the linear attenuation coefficient of the measured points was the average linear attenuation coefficient value. Averaged radiation doses measured at spot $X, D_{x}$. Eq. (4) expressed as an exponential function of $x$ :

$$
\frac{1}{2}=\frac{D_{x}}{D_{0}}=e^{-\mu \times H V L}
$$

where $D_{0}$ is the averaged doses measured at $\mathrm{G}(0,0), \mu$ is the attenuation coefficient of air in $1 /$ meter. HVL means the half value layer (unit: meter) for the 6-MV of TOMO treatment room. $\mathrm{X}$ is the distance between spot $G$ and sport $X$ in meter.

\section{Results and discussions}

\subsection{Full factorial design (FFD)}

The original 3 TLD readings calculated by various radiotherapy beam doses $(1,2,4$, and 10 cGy) randomly assigned to TLDs as listed as Table 3 . The square of correlation coefficient $\left(R^{2}\right)$ was estimated among the eight groups.

High $R^{2}$ values of every regressed fit, the $R^{2}=0.99039$ of Group 4 was the largest $R^{2}$ among the other groups as clearly described. In the FFD, the group has the maximum S/N ratio that was the best optimum group among these groups. Figure 3 illustrates that the derived linear regression fitted well. Group 1 was the best suited because of the largest $\mathrm{S} / \mathrm{N}$ ratio $(\eta), 0.590$. The degree of linearity was specified by the derived coefficient of determination $\left(R^{2}\right)$. The $R^{2}$ of the regression line was the highest $\left(R^{2}=0.97793\right)$, indicating that this group achieved the best compromise between Stdev and $\beta$. Restated, the high regressive low Stdev and slop $\beta$, which meant the highest reproducibility, were both optimal for the calculated doses versus Harshaw 3500 readings for various doses from TOMO linac.

Analysis of X-ray leakage and scattering from the linac of the medical university has been reported in several previous studies [3-9]. The dose calibration line of group $1\left(130^{\circ} \mathrm{C}\right.$ initial temperature, $11^{\circ} \mathrm{C} / \mathrm{s}$, and maximum temperature $230^{\circ} \mathrm{C}$ ) was plotted as a function of TLD measurement, as shown in Fig. 3 . The result was obtained using the Excel linear regression function [17]. 


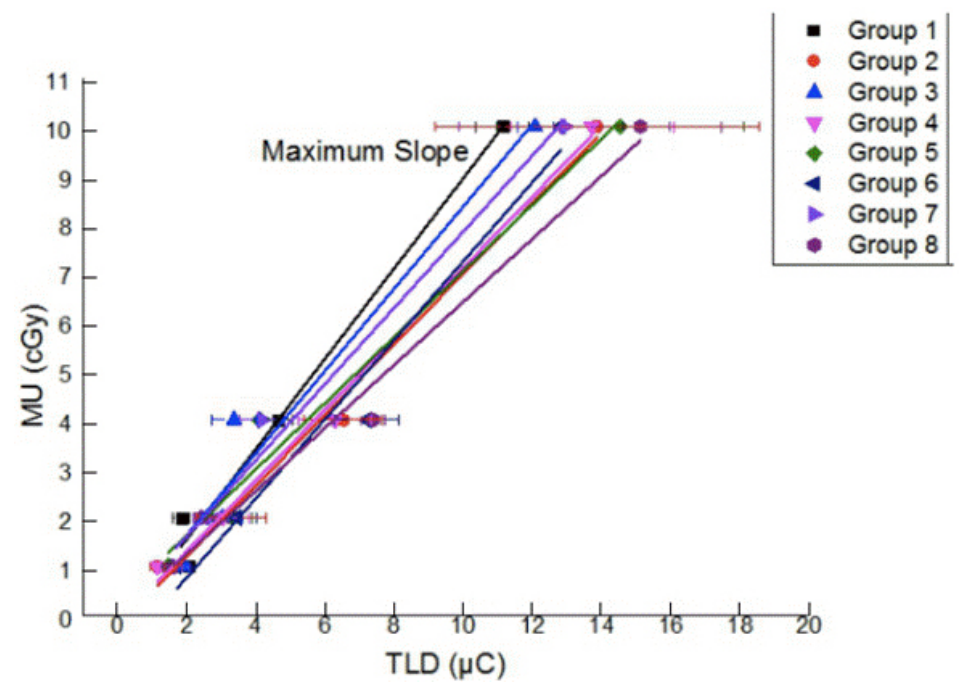

Fig. 3. The derived linear regression fit of the eight groups.
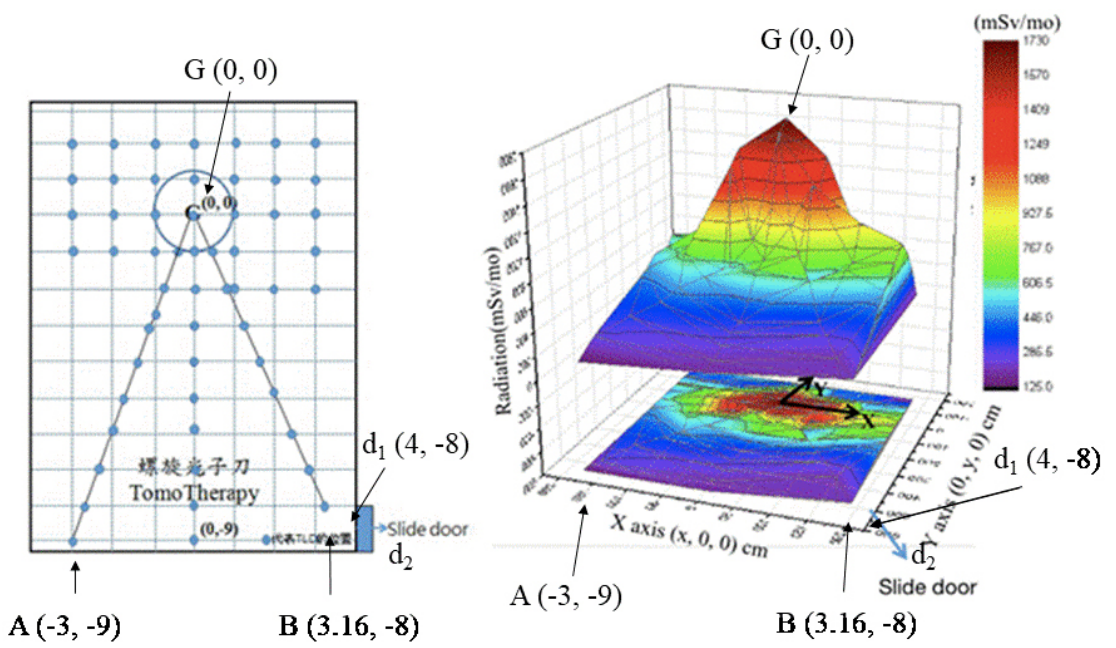

Fig. 4. Three-dimensional distributions of the treatment room averaged environmental radiations, mapped via colored profiles.

Three TLDs were combined in 1 bag to evaluate environmental radiations in the TOMO facility, with 321 TLDs representing 107 measurement spots. Figure 4 shows 3-dimensional distributions of environmental radiations among the treatment room to reflect various environmental radiations that were mapped using intensity colors.

Figure 4 shows that decreases in environmental radiations were related to the increase in the distance to the gantry head ranging from the highest $1730 \pm 140 \mathrm{mSv} / \mathrm{mo}$ at $\mathrm{G}(0,0)$ to the lowest of $104 \pm$ $10 \mathrm{mSv} / \mathrm{mo}$ at $D_{1}(4,8)$. The red zones were the "hottest areas", so that other colors represented different intensities of smoothed radiations. In addition, environmental radiation at $D_{1}$ was approximately $6.09 \%$ of that at the hottest $\mathrm{G}$. The range of color indices was $10^{3} \mathrm{mSv} / \mathrm{mo}$ (red) to $100 \mathrm{mSv} / \mathrm{mo}$ (blue), which represents the intensity of environmental radiations from dramatically strong to light, respectively. Other colored zones of Fig. 4 represent different intensities of the smoothed $\gamma$-ray radiations among the TOMO 
Table 4

The averaged environmental radiations $(\mathrm{mSv} / \mathrm{mo})$

\begin{tabular}{lc}
\hline Location & Radiation $(\mathrm{mSv} / \mathrm{mo})$ \\
\hline Control area & \\
Treatment room & $1730 \pm 140$ \\
G $(0,0)$ & $171 \pm 15$ \\
A $(-3,-9)$ & $211 \pm 19$ \\
B $(3.16,-8)$ & $104 \pm 10$ \\
Treatment room (inside slide door) $D_{1}(4,-8)$ & \\
Public area & \\
Waiting room & $0.16 \pm 0.03$ \\
$\quad$ Treatment room (outside ceiling) $\mathrm{D}_{2}$ & $0.15 \pm 0.02$ \\
$\quad$ Sofa (W5) & $0.15 \pm 0.03$ \\
$\quad$ Clock (W6) & \\
Achieves room & $0.13 \pm 0.02$ \\
$\quad$ Above cabinet (A1) & $0.15 \pm 0.02$ \\
Above cabinet (A2) & \\
Control room & $0.16 \pm 0.05$ \\
$\quad$ Computer (C3) & $0.14 \pm 0.02$ \\
Ceiling (C4) & \\
MRI & $0.11 \pm 0.03$ \\
$\quad$ Control room (M7) & $0.16 \pm 0.04$ \\
Computer room (M8) & $0.15 \pm 0.02$ \\
Taichung City (TC1) & $0.14 \pm 0.04$ \\
Taichung City (TC2) & \\
\hline
\end{tabular}

treatment room. The environmental radiation at each detected spot decreased from spot $\mathrm{G}$ to spot $\mathrm{A}$ and B with experimental errors less than $20 \%$. Outside the treatment room deviation was larger than $20 \%$. Table 4 lists the averaged environmental radiations ( $\mathrm{mSv} / \mathrm{mo}$ ) measured due primarily to the dataset of 107 spots at the TOMO facility.

The TLD measurement within the TOMO facility indicated that the radiations varied markedly in the range of $1730 \pm 140 \mathrm{G}(0,0)$ to $0.11 \pm 0.03(\mathrm{M} 7) \mathrm{mSv} / \mathrm{mo}$. That is, the TLD measurement results were unexpected during the TOMO operation. This finding indicated extra high-energy X-rays were coming strongly forward from the target of the TOMO gantry head. The high environmental radiations caused extra risks to the public. So that maintenance workers and medical staff MUST prohibit entering the treatment room of this control area during TOMO operation. The environmental radiation was $0.16 \pm$ $0.03 \mathrm{mSv} / \mathrm{mo}$ at the $D_{2}$, which was out of the sliding door of the control area (Fig. 1b).

Environmental radiation at $\mathrm{G}(0,0)$ was extremely high, which was 11,500 times more than $0.15 \pm$ $0.02 \mathrm{mSv} / \mathrm{mo}$ that was measured in Taichung City. In addition, the shield-effect of the sliding door at $D_{1}$ was 65.0. That is, placing the motorized door (cf. Fig. 1b) effectively reduced the environmental radiation at spot $D_{2}$ by a factor of $65.0(104 / 0.16=65.0)$. This was because the 45 -cm-thick Fe could effectively attenuate extra photons. Reasonably, the measured radiations were in agreement with published studies [5,7].

Over the ten-month survey in the working areas, data showed that environmental radiations in W5 (sofa of waiting room), W4 (clock of waiting room), C3 (computer of control room), and C4 (ceiling of control room) were approximately the same as the $0.16 \pm 0.04 \mathrm{mSv} / \mathrm{mo}$ of the environmental background and $0.15 \pm 0.04 \mathrm{mSv} / \mathrm{mo}$ that were measured at the our lower background laboratory where was far from the facility (Fig. 2). In addition, these values were in agreement with the published data of those measured via the TLD-100H and IC, which ranged from 0.07 to $0.15 \mu \mathrm{Sv} / \mathrm{hbecause}$ the low concentration of natural radionuclides was measured at Taichung City [5]. This was primarily because Fe effectively attenuated the extra photons. The estimated radiations reasonably in good agreement with those in TC1 


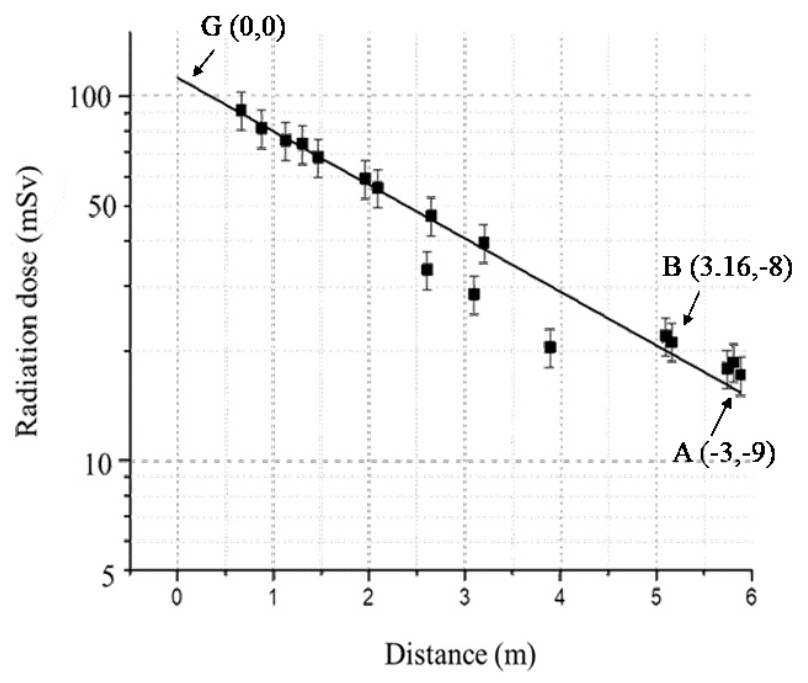

Fig. 5. Half-value layer of the TOMO treatment room.

and TC2. Furthermore, the environmental radiations on the upper floor $(2 \mathrm{~F})$ of the TOMO facility, that was immediately above gantry head $\mathrm{G}(0,0)$, was $0.14 \pm 0.03 \mathrm{mSv} / \mathrm{mo}$.

\subsection{Dose estimation of radiologist in control room}

Figure 4 shows the spots closest to the medical staff on duty among the computer of the control room (C3) of the public area. It was reasonably assumed that extra photons penetrated far into 120-cm-thick $\mathrm{RC}$ as well as $20-\mathrm{cm} \mathrm{Pb}$ wall to enter the control room (C3), $0.16 \pm 0.05 \mathrm{mSv} / \mathrm{mo}$. As the TOMO facility at hospital was 12 months/year, the annual "extra" doses for staff stationed at the facility (Fig. 2) was $0.16 \mathrm{mSv} / \mathrm{mo}$ times $12 \mathrm{mo} / \mathrm{y}$ equaled to $1.92 \mathrm{mSv} / \mathrm{y}$ (16 ICRP 60, 1991). The environmental radiation at spot C3 among the control area far exceeded the dose rate of $50 \mathrm{mSv}$ per year in the working areas $[14,16]$. The annual environmental radiations among the public areas of the sofa, waiting room (W5) as well as MRI control room (M7) were 1.80 and $1.32 \mathrm{mSv} / \mathrm{y}$, respectively.

Comparison with published data showed no main public health impact. That is, no significant contributions were detected during TOMO operations in the public area. These data demonstrated that the "extra" x-rays were not a health concern for staff or the public at hospital during the linac operation. In addition, actual environmental radiations outside of the TOMO facility, such as the Axesse linac (cf Table 4, located at B1), are worth measuring in further studies.

All measurements were performed by attached TLDs at location $\mathrm{G}(0,0), \mathrm{A}(-3,-9)$, and B $(3.16$, -8 ) at 0.2 to 1 meter intervals along the G-A and G-B straight lines (Fig. 4). Environmental radiation of the $\mathrm{B}(3.16,-8)$ was $211 \pm 19 \mathrm{mSv} / \mathrm{mo}, 12.2 \%$ of that at $\mathrm{G}$ point, was the hottest. The distance from $\mathrm{G}$ to B was 5.1 meters. The HVL was obtained from Fig. 5 as well as Eq. (4) with extrapolating the part of the curve with a y value to a point on the G-A and G-B lines. So that HVL of the 6-MV photons was 2.09 $\pm 0.32 \mathrm{~m}$ at the ceiling of the TOMO linac treatment room.

\section{Conclusions}

The FFD was successfully applied to optimize the Harshaw 3500 reader. The $\mathrm{S} / \mathrm{N}(\eta)$ increased rapidly from -0.246 (original setting) to 0.590 of the optimization recommended by FFD. The suggested optimal 
parameters were preheating at $130^{\circ} \mathrm{C}$, with a heating rate of $11^{\circ} \mathrm{C} / \mathrm{s}$; the maximum temperature was $230^{\circ} \mathrm{C}$ for the environmental measurements using the TLD approach. The environmental radiations in the TOMO facility were successfully measured, and the annual doses for the radiologists were also elucidated. The TLD-100H approach was an effective method for measuring environmental radiations in the TOMO facility. The radiations in the treatment room indicated a function of distance from the center of TOMO.

In addition, a 45-cm-thick steel plate (Fe) was capable of suppressing the photon doses and provided adequate shielding for the public. The environmental radiation rates ranged from $1730 \pm 140$ to $0.11 \pm$ $0.03 \mathrm{mSv} / \mathrm{mo}$ during a ten-month survey. This is in agreement with $50 \mathrm{mSv} / \mathrm{y}$, the annual maximum doses reported in previous studies. In addition, the wall consisted of $\mathrm{RC}$ and $\mathrm{Pb}$, between the control as well as the public area, which effectively protected staff and the public during the TOMO operation. To assess environmental radiations, TLDs have been established as a useful and valuable dosimetry system.

\section{Acknowledgments}

The authors thank the TOMO staff of the hospital for their useful and valuable support of this research without any reservation.

\section{Conflict of interest}

None to report.

\section{References}

[1] MOH, Available at https://dep.mohw.gov.tw/dos/lp-4927-113.html. 2021.

[2] Chen LF, Tseng HC, Pan LK, et al. Evaluating environment radiations at Axesse linac undergoing NPC treatment of VMAT. Comput Assist Surg. 2016; 21(S1): 79-83.

[3] Tseng HC, Liu WS, Huang HS, et al. Spatial distributions of environmenral radiations at medical linac undergoing treatment of vmat using taguchi method. J Radioanal Nucl Chem. 2016; 307: 1635-1639.

[4] Tseng HC, Liu WS, Lin JB, et al. Evaluating air kerma at a medical cyclotron after refined shielding design using the TLD approach. J Nucl Sci Technol. 2013; 50(6): 599-605.

[5] Changlai SP, Tsai HH, Tsai SC, et al. Environmental radiation detected at Lin Shin hospital in Taichung during the Fukushima nuclear power plant accident. J Radioanal Nucl Chem. 2012; 291(3): 859-863.

[6] Chen CY, Liu Kuo CL, Chen HH, et al. Optimizing the TLD-100 reading system for various radiotherapy beam doses using the Taguchi methodology. Appl Radiat Isot. 2010; 68: 481-488.

[7] Le Y, Weng JH, Lee TM, et al. TLD environmental radiation of the NEW scanner facilities of the Nuclear Medicine Department of Medical University. Technol and Health Care. 2020; 28: S151-S160.

[8] Lin HC, Lai TJ, Tseng HC, et al. Evaluating doses of multi-slice CT in brain examinations using various methods. Comput Assist Surg. 2017; 22(S1): 54-60.

[9] Sadeghi M, Faghihi R, Sina S, Developing an optimum protocol for thermoluminescence dosimetry with GR-200 chips using taguchi method. Radiat Prot Dosim. 2017; 175(2): 284-294.

[10] Das T, Venkatesh MP, Kumar TMP, et al. SLN based alendronate in situ gel as an implantable drug delivery system - A full factorial design approach. J Drug Deliv Sci Technol. 2020; 55: 101415.

[11] Verma U, Rajput R, Naik JB. Development and characterization of Fast Dissolving Film of Chitosan embedded Famotidine Using $3^{2}$ Full Factorial Design Approach. Mater Today Proc. 2018; 5: 408-414.

[12] Madrid JF, Lopez PGE, Abad LV. Application of full-factorial design in the synthesis of polypropylene-gpoly (glycidyl methacrylate) functional material for metal ion adsorption. Radi Phys Chem. 2017; 136: 54-63.

[13] Beauchamp Y, Thomas M, Youssef YA, et al. Investigation of cutting parameter effects on surface roughness in lathe boring operation by use of a full factorial design. Computers \& Industrial Engineering. 1996; 31(3-4): 645-651.

[14] Chung Shan Medical University, Available from: http://english.csmu.edu.tw/bin/home.php. 2021. 
[15] Tomotherapy Hi-Art, available at: https://delec.com.ar/panel/wp-content/uploads/Hi\%C2\%B7Art-Product-Data-Sheet.pdf. 2021.

[16] International Commission on Radiological Protection, Recommendations of the International Commission on Radiological Protection. Publication 103, Annals of ICRP Vol. 37 (2/4), Pergamon Press, Oxford, 2007.

[17] Excel, available at https://www.microsoft.com/zh-tw/microsoft-365. 2021. 